\title{
Relationship Between Audit Manager Experience and Compliance Audit Outcomes
}

\author{
Frank Nation \\ University of Illinois in Springfield \\ Danny Williams \\ University of Illinois in Springfield \\ Mark Buxton \\ University of Illinois in Springfield
}

This study examines variables that effect on Illinois Auditor General compliance audit outcomes. Specifically, the compliance reports the Auditor General staff complete. The variables added focus on the experience level of each audit manager and how that experience affects audit outcomes including; material findings, immaterial findings, and total findings. The results of this study show there is a significant relationship between an audit managers prior experience and the resulting findings. Additionally, this study confirms and adds further data to work done by Branson, Nation, \& Stephens (2016) in which audit hours have a significant positive relationship with audit findings.

Keywords: Internal Audit, Audit Manager Experience, Audit Manager Tenure

\section{INTRODUCTION}

The State of Illinois has hundreds of agencies that are required by statutory law to have a biennial audit conducted and released by the Office of the Auditor General (OAG). This means the OAG must release approximately 150 audits each year (Illinois Auditor General, 2018). This is an unrealistic number of audits to complete using only the OAG staff. Some audits the OAG will contract out to Certified Public Accountant (CPA) firms. This outsourcing is necessary to keep up to date with their audits program. These subcontracted auditors are known as Special Assistant Auditors (SAA). There are three divisions within the OAG, financial/compliance, performance, and information systems. This paper focuses on the financial/compliance division, specifically, the compliance examinations that are released.

Effective compliance audits can save the State and its taxpayers' tremendous amounts of money by improving controls or uncovering a fraud. The process for completing a state agency compliance audit is similar to that for public sector audits. Auditors with more experience perform the audit planning. This includes selecting sample sizes, planning for risks, and general information gathering. Auditors with less experience will perform substantive tests and analytical procedures to identify weaknesses in controls or breaches in statutory law. A supervisor reviews results once testing is completed. This supervisor is the 
auditor who normally performs the planning of the audit. After the first review, the manager will perform a final third review of the work-papers. The manager will also make a final determination what findings will go in the final compliance report and what findings will be included in the immaterial letter. The findings in the compliance report will become public knowledge and will go before the Legislative Audit Commission (LAC) who discusses the findings with management of the agency in question. The immaterial letter is not public knowledge however and is only available to the OAG staff and the agency under audit.

Compliance audit managers possess greater audit experience than their peers. The objective of this paper is to examine the effect of manager experience on audit quality. Previous research has defined audit quality as the number of audit findings. The primary focus of this study is to examine the relationship between state compliance audit managers' level of experience and total compliance audit findings. This study will also sharpen the focus of the research by tightening the level of measurement of the dependent variable by measuring not only total findings but immaterial findings as well.

This study examines not only audit manager overall experience, but also repetitive experience with the same agency. What is the effect on audit quality if an audit manager has worked on the same auditee in the prior examination period? There are positives and negatives to auditor change. By switching managers of an audit, you help minimize the possibility of collusion between the OAG and management of the State agency. The question is, do the positive effects of keeping the same manager on an audit, outweigh the negative possibilities?

\section{LITERATURE REVIEW}

A study by Branson, Decker, and Green (2011) looked into the type of auditor and its impact on the amount of findings reported to the Legislative Audit Commission (LAC). Compliance audit reports of the audits of 24 agencies audited between 2000 and 2009 provided the data for this study. This sample of 24 was chosen because these were the agencies that were audited by both the OAG and SAA of subcontracted CPA firms. The study found that OAG auditors found significantly more compliance audit findings than SAA auditors (Branson, Decker, \& Green, To Find or Not to Find: Public Accounting Auditors versus Governmental Auditors, 2011).

Branson, Nation, \& Clark (2016) extended Branson, Decker, \& Green (2011). The objective was to determine what other variables affected the amount of audit findings in State government reporting. The primary independent variable was the size of the organization under audit. The agency size was measured by the number of employees. The researchers hypothesized that the more employees an agency has the more complicated agency operations will become, increasing the number of compliance audit findings. The second variable added was the number of mandates affecting an agency. The more complex policies and procedures become the more difficult it becomes to follow policies and procedures as intended. The results confirmed the hypothesis that the size of the agency and the number of mandates affecting the agency significantly influenced the number of findings in an agency's compliance examination (Branson, Nation, \& Clark, 2016).

Branson, Nation, \& Stephens (2016) performed a third study related to Branson, Decker, \& Green's (2011) original study. The study hypothesized that the number of hours spent on a compliance examination is related to the number of current year audit findings. The data sample collected was from the 25 largest Illinois agencies during 2005 to 2013. To measure size of agencies, they used the amount of appropriations received from the General Revenue Fund. Branson, Nation, \& Stephens (2016) included a sample 135 compliance audit examinations. A problem arose during the statistical analysis of the data however. They found it impossible to find an exact starting date for the audits. To remedy the issue, the researchers selected June 30 because it is the end of the State's fiscal year. This is problematic since some audits may not start at that exact date. For the end of the audit, Branson, Nation, \& Stephens (2016) used the exit conference as the mark for the official end of the audit engagement. The data analysis supported their hypothesis that the time spent on the engagement affects the number of state agency compliance audit findings (Branson, Nation, \& Stephens, 2016). 
Suhayati (2012) proposed that the competitive bid process the SAA firms endure influences the relationship between the number of findings and audit time spent. The study examined the competitive bidding process whereby audit firms bid for SAA audit work. This paper found that the incentives present in the competitive bid process may lead to audit quality deterioration resulting from time and budget constrictions imposed by low bids. This causes time restraints on the SAA's leading to decreased available audit hours (Suhayati, 2012).

Branson, Nation, \& Rothe (2018) extended prior studies by Branson, Nation, and Green (2011), Branson, Nation, and Clark (2016) and finally Branson, Nation, Stephens (2016). Specifically, Branson, Nation, \& Rothe (2018) added two variables; the amount of appropriations an agency receives and the length of the examination period between compliance audits. The study found evidence supporting the hypothesis that appropriations affect the number of findings. However, the results failed to support the hypothesis that the length of time between compliance examinations affected audit findings (Branson, Nation, \& Rothe, 2018).

A study by Libby and Frederick (1990) investigated how experience affected auditor's knowledge and decisions throughout the course of an audit. Libby and Frederick "found that more experienced auditors exhibited more complete knowledge of financial statement errors by generating a greater quantity of accurate explanatory hypotheses." (Libby \& Frederick, 1990, p. 350). This research supports this study's hypothesis that more experienced managers at the OAG would find more total findings through the course of an audit compared to their less experienced co-workers.

Abdolmohammadi and Wright (1987) focused on how auditor experience affected the outcome on different tasks. The theoretical model suggests that the effects of experience are more noticeable with increasing task-complexity. Auditors performed tasks separated into three levels of task-complexity; structured, semi-structured, and unstructured. Unstructured tasks are unique with few guidelines available such as decision-making on requiring adjustments to financial statements. Semi-structured tasks are repetitive with a 'reasonably defined problem' including tasks such as determining tolerable rate for substantive testing. Finally, structured tasks are routine and well-defined such as selecting sample sizes for substantive testing. The results showed significant differences between experienced auditors and inexperienced auditors when performing all tasks, indicating that as the task became more complex, the greater the difference between experienced and inexperienced auditor's work. (Abdolmohammadi \& Wright, 1987).

A study conducted by Shelton (1999) investigated how the dilution effect influences auditor decisions. The study investigated whether an auditor's experience level moderates the dilutive effect of irrelevant information on auditors' judgments. Often auditors receive both relevant and irrelevant information about a decision. Dilution occurs when the irrelevant information degrades the auditor's judgment with respect to the decision. One experimental participant group received only relevant audit evidence while the other group received both relevant and irrelevant evidence. Shelton's results indicated a significant dilution effect for less experienced auditors but not for the more experienced auditors (Shelton, 1999).

Weber (1980) studied computer controls by electronic data processing (EDP) auditors. This study found that experienced auditors could recall a significantly higher number of controls over their less experienced co-workers (Weber, 1980). This study found the more experience an auditor has, the more knowledge they can access from previous audits that would help them make determinations on current audits.

Ho (1994) conducted a study similar to that of Shelton (1999). Ho's work looked into how the experience level of auditors affects auditor judgement when assessing going-concern of a company. Historically, "studies suggest significant agreement among auditors' going-concern judgments." (Ho, 1994, p. 160). This study showed there was a significant difference between experienced auditors and less experienced auditors and their judgements on going-concern. The sample consisted of one hundred and fifty-six auditors of varying experience levels measured by the number of months of current employment. The participants were separated by experience level into experienced and inexperienced groups. The results showed that there is not a consensus for going-concern between experienced and less-experienced 
auditors. Additionally, "more experienced auditors generated more positive going-concern judgements." (Ho, 1994, p. 167).

Deis Jr. and Giroux (1996) studied the effect of auditor change on an audit. Specifically, how that change would affect fees, hours, and quality. This study measured working papers from audits performed on Texas public schools called quality control reviews. These reviews are used to obtain a measurement of quality by the Texas Education Agency. Their results indicated that initial audits were associated with lower fees, higher quality, and higher audit hours. When auditors change, fees are relatively lower than audits performed multiple years in a row. However, audit hours and quality are significantly higher when an auditor change occurs. The authors attributed this to a "low-ball" initial offer to receive the audit contract. Audit hours increased because of auditor unfamiliarity with the schools' processes and procedures. By spending more time on the audit in the first year of their engagement, the auditors achieved a higher quality audit (Deis, Jr. \& Giroux, 1996). The study also found audit quality actually declined after longer periods of audit tenure, due to what Mautz and Sharaf's (1961) seminal book described as the complacency theory (Mautz \& Sharaf, 1961). Hence, the study's findings support the proposal that audit managers' conducting the same engagement in two consecutive audit cycles are like to report fewer findings in subsequent audits of the same client agency.

A study conducted in Korea examined the effects of a mandatory audit firm rotation on several dependent variables including audit fees. From 2006 to 2010, public firms in Korea were required to contract a new audit firm each year. Kwon, Lim, and Simnett (2014) found that due to mandatory rotation of audit firms, audit hours, and therefore audit fees, increased in the post 2006 Korean mandatory rotation regime. Nevertheless, audit quality remained unchanged between the pre - and post - 2006 audits (Kwon, Lim, \& Simnett, 2014). This supports evidence from Deis Jr. and Giroux about the first year of an auditor's tenure with a client.

Geiger and Raghunandan's (2002) study found different results in their study of mandatory audit firm rotation effects on audit quality. The authors sample companies entering into bankruptcy from 1996-1998. They examined the relationship between auditor tenure and the type of audit opinion issued. Their results indicated that audit failures were significantly more likely in the earlier years of the auditor-client relationship than there were when auditors served clients for longer time periods. (Geiger \& Raghunandan, 2002). These results seem to contradict Kwon, Lim, and Simnett's (2014) results.

Carcello and Nagy (2004) conducted a similar study supporting Geiger and Raghunandan's (2002) results. Carcello and Nagy (2004) sampled companies who were found to have fraudulent financial statements from $1990-2001$. The results showed that mandatory rotation of audit firms could have a negative impact on audit quality. The study found that there was a higher likelihood of fraudulent financial statements in the initial years of the auditor-client association (Carcello \& Nagy, 2004). This result indicates that firm rotation may provide lower audit quality despite auditor efforts to learn a new client's operations with the intended effect of improving audit quality.

Stephen Aikins (2017) study of the effect of the number of audit hours on government internal audits hypothesized that there is a relationship between the amounts of audit time invested and the number of internal audit recommendations produced annually. The results indicated a significant relationship between time invested and number of recommendations (Aikins, 2017). Aikins added, "This is not surprising, considering the fact that the efforts of audit management are expected to directly result in audit performance." (Aikins, 2017, p. 167).

Palmrose (1986) examined whether there is a systematic relation between audit firm size (in terms of both absolute size and relative market shares) and audit fees. In addition to the main finding, the study produced a relevant incidental result supporting the argument that audits with more audit hours reflect greater evidence acquisition leading to a higher level of assurance (Palmrose, 1986, p. 108).

\section{HYPOTHESIS}

This paper examines the effect of two independent variables. The first is the audit manager's general experience level. This variable measures the individual's time spent as an audit manager. The second 
independent variable is the manager's experience with the client agency. This variable is measured at two levels, audit managers who have audited the same client agency in two consecutive engagements versus audit managers who have not audited the same client agency engagement in the prior examination period (two years previous). The study will examine two dependent variables. The first is the total number of compliance audit findings. This includes material findings in the compliance report as well as immaterial findings in the immaterial letter. The second dependent variable is the percentage of immaterial findings to material findings. The following hypotheses are based upon the literature reviewed as well as from experience at the Auditor General.

As $\mathrm{OAG}$ employees gain more experience they increase their audit-domain knowledge from previous audit involvement. The increased experience provides a greater base of declarative and procedural knowledge from which to draw conclusions. These types of knowledge allow auditors to perform audits more efficiently and effectively. This will lead experienced auditors to produce more total audit findings than their less experienced coworkers. Thus, the authors hypothesize:

\section{H1: There is a positive relationship between audit manager experience and the total number of findings.}

Previous research (Ho 1994) and conversations with current managers, suggests to the authors that experienced managers look more for bigger issues than opposed to smaller, isolated mistakes made by agencies. Thus, the more experienced the managers are, the more likely they will be to classify findings as immaterial. These 'smaller' mistakes will then be included in the immaterial findings letter, informing the agency of an audit issue that is not material enough to warrant inclusion in the final report. Hence, the authors hypothesize:

H2: There is a positive relationship between audit managers experience and the percentage of immaterial findings.

Previous research exhibits mixed results on the subject of audit rotation. Deis Jr. and Giroux (1996) found declines in audit quality with increasing auditor tenure. Geiger and Ragahunandan (2002) reported that there were fewer audit failures with increasing tenure. Kwon, Lim, and Simnett (2014) found that when the firm rotated, audit hours increased while quality remained the same. The researchers chose to test the hypothesis that managers performing sequential audits of the same agency will report fewer total findings. This presents the most conservative hypothesis for testing:

H3: There is a negative relationship between audit managers having prior year experience and the total number of findings.

As auditor tenure with agencies increases audit quality should deteriorate (Deis, Jr. \& Giroux, 1996) (Carcello \& Nagy, 2004) (Geiger \& Raghunandan, 2002). Managers performing sequential audits will find fewer material findings but low priority immaterial findings may continue to be reported for several audit cycles. Managers performing sequential audits of the same agency, will exhibit an increasing percentage of immaterial findings. Agencies will focus on correcting any material findings first since those are the higher priority. Therefore, immaterial findings accumulate. Thus, the number of material findings declines, while maintaining the immaterial findings prompts the hypothesis:

H4: There is a positive relationship between auditing managers having prior year experience and the percentage of immaterial findings.

\section{METHODOLOGY}

This research studied the effect of three independent variables on two dependent variables by utilizing a linear regression model and analysis of variance (ANOVA) methodology using SPSS 25 to perform 
data analysis. The research design revolved around the use of two regression studies to examine the effects of the same independent variables on a different dependent variable. The proposed hypotheses suggest that the degree of audit experience as well as the degree of audit manager experience with the same client in subsequent years affects their judgment about material and immaterial findings. This effect, in turn, should influence the number and percentage of audit findings reported in the compliance audit findings.

The authors selected their sample from Illinois State agencies from the previous six audit cycles (Fiscal Years 2016/2017 - Fiscal Years 2011/2012). The OAG's record retention policy mandates the deletion of electronic files every six years, which proved to be a limitation of this research. The selected sample size consisted of 136 compliance audits performed by the OAG staff. The researchers excluded audits performed by SAA because such audits did not disclose the level of expertise of the audit manager. OAG documents the level of expertise of its audit managers in their performance reports related to promotion. Hence, the use of OAG files provided ample, qualified subjects for the study and was more likely to include repeat audits.

The first independent variable is an audit manager's experience level. The Director of the Financial/Compliance Division at the OAG provided a report summarizing each audit. Information included in this report summary included the names of the audit managers for each audit. The researchers contacted the OAG managers, asking them to provide the number of years each had been employed at the level of Auditor IV. Auditors start managing OAG staff audits once their rank is that of Auditor IV. The researchers used the manager's time as an Auditor IV as a measure of experience. The researchers were fortunate to find that all of the managers listed over the past six years remained employed by the OAG and responded to the survey.

Another independent variable of this study measured repeated audit management. This variable measured the number of times a manager performed subsequent audits of the same agency. A dummy variable value of one indicated an audit that was performed by the same audit manager as the previous audit, while a value of zero meant that was the audit manager's first time for that agency. The Director's report mentioned above provided this information.

The final independent variable was the number of audit hours it took for the audit to be completed. The printed report had each audit engagement's budgeted and actual audit hours. For the purposes of this study, the authors used the number of actual audit hours as the measurement of time required for audit completion. The dependent variables used in this study were all identified from OAG data.

This research regressed the independent variables against two dependent variables to study the four specified hypotheses. The first dependent variable is the number of material findings. This is the dependent variable associated with $\mathrm{H} 1$ and $\mathrm{H} 3$. These are audit findings included in a compliance audit report and are published on the auditor general's website. The second dependent variable studied is the percentage of immaterial findings. These findings are not public knowledge and do not go into the same compliance report as material findings. Instead, immaterial findings are placed into the immaterial letter that is sent to the respective agency. This letter makes the agency aware that these findings are considered an issue but not enough to warrant placement in the compliance report. These findings are associated with $\mathrm{H} 2$ and H4. Total findings were measured by adding the material findings and immaterial findings for each audit. The researchers determined the percentage of immaterial findings by dividing the number of immaterial findings by the number of total findings.

\section{RESULTS}

The researchers proposed a regression model including independent variables representing the variable of interest, audit manager experience level (in total and with respect to the previous experience with a client), the actual audit hours. The researchers specified the regression models as follows:

$Y_{i}=b_{0}+b_{1} \mathrm{X}_{1}+b_{2} \mathrm{X}_{2}+b_{3} \mathrm{X}_{3}+\varepsilon$ 
where $\mathrm{Y} 1=$ Total number of audit findings, $\mathrm{Y} 2=$ Percentage of immaterial audit findings, $\mathrm{X} 1=$ (Experience), X2 = (Prior Year Experience), and X3 = (Audit Hours).

Significance tests for regression coefficients rely on the data's adherence to the four central assumptions related to linear regression: linearity, normally distributed error terms, independence, (and multi-collinearity), and homogeneity of variance (Nau, 2018). The first assumption is that the dependent and independent variables constitute a linear relationship. Evaluating a P-P plot of regression standardized residuals allows for evaluation of linearity. The P-P plot of regression standardized residuals (expected versus observed, un-tabulated) revealed that the data departed only slightly from linearity. Another assumption of regression analysis is normal distribution of the residuals. Testing this assumption involves evaluating a histogram plot of the residuals of the regression line. The histogram of the residuals (untabulated) exhibited an approximately normal distribution of the error terms. This supports the reliability and validity of the regression beta-coefficients. Third is the assumption of statistical independence. The Durbin-Watson test examines the data for autocorrelation, a sign of a 'lack of statistical independence'. The Durbin-Watson statistic can assume values between zero and four. Durbin-Watson statistic values around two indicate there is no significant autocorrelation in the data. The regression analysis produced a Durbin-Watson statistic of 2.129 (un-tabulated) indicating that there is no significant 'lack of statistical independence' in the data. Additionally, multi-collinearity is also a sign of a 'lack of statistical independence'. This study evaluated the Variance Inflation Factor (VIF) tests for excessive multicollinearity. A widely accepted rule of thumb is that a VIF of four or more requires further attention (The Pennsylvania State University, 2017). Review of the regression results indicated that multi-collinearity was not excessive (Table 1-3, and 2-3 below). Finally, the data must conform to the homogeneity of variance assumption. A plot of residuals versus predicted values is diagnostic for this assumption. Review of a plot of residuals versus predicted values (un-tabulated) revealed that these data conform to the assumption of homogeneity of variance (Nau, 2018).

The regression models included the following independent variables: the audit manager's years of experience overseeing staff audits (Experience), whether the manager oversaw the same engagement in the prior engagement cycle (Prior Year Experience), and the actual number of audit hours required (Audit Hours).

Model 1 presents the results of the regression using the total number of audit findings as the dependent variable (See Tables 1-1, 1-2, and 1-3). This model examines the relationship of the variables for $\mathrm{H} 1$ and $\mathrm{H} 3$. The regression is significant $(\mathrm{F}(3,132)=102.707, \mathrm{p}<.001)$ and allows users to predict approximately 69.3 percent of the variability observed in the dependent variable. With respect to the variable of interest for this regression, regression one reveals that manager experience has a significant positive relationship with the total number of findings at a significance level of .10 ( $\beta=.177, t(1.695), p$ $=.099$ ). In other words, as manager experience increases, the total number of findings increases as well. In addition, audit hours was significant at a level of $.05(\beta=.006, \mathrm{t}(17.023), \mathrm{p}<.000)$. Finally, managers with prior year experience exhibit a significant negative relationship with the total number of findings at a significance level of $.10(\beta=-1.365, \mathrm{t}(-1.708), \mathrm{p}=.090)$. Hence, managers who have a second sequential year of experience with the same agency are likely to exhibit fewer total findings. These results support both $\mathrm{H} 1$ and $\mathrm{H} 3$.

\section{TABLE 1-1 MODEL SUMMARY}

\begin{tabular}{|l|c|c|c|}
\hline Model & R & R Squared & Adjusted R Squared \\
\hline 1 & .837 & .700 & .693 \\
\hline
\end{tabular}


TABLE 1-2

ANOVA

\begin{tabular}{|l|c|c|c|c|c|}
\hline Model 1 & $\begin{array}{c}\text { Sum of } \\
\text { Squares }\end{array}$ & df & Mean Square & F & Sig. \\
\hline Regression & 5768.169 & 3 & 1922.723 & 102.707 & $.000^{\mathrm{b}}$ \\
\hline Residual & 2471.096 & 132 & 18.720 & & \\
\hline Total & 8239.265 & 135 & & & \\
\hline
\end{tabular}

a. Dependent Variable: Total Findings

b. Predictors: (Constant), Audit Hours, PY Ex., Experience

TABLE 1-3

COEFFICIENTS

\begin{tabular}{|l|c|c|c|c|c|c|}
\hline Model 1 & B & Std. Error & Beta & T & Sig. & VIF \\
\hline (Constant) & -.696 & .751 & & -.927 & .355 & \\
\hline Experience & .177 & .107 & .086 & 1.659 & .099 & 1.176 \\
\hline PY Ex. & -1.365 & .799 & -.088 & -1.708 & .090 & 1.155 \\
\hline Audit Hours & .006 & .000 & .820 & 17.023 & .000 & 1.021 \\
\hline
\end{tabular}

Model 2 shows the results of the linear regression model using percent of immaterial findings as the dependent variable (See Tables 2-1, 2-2, and 2-3). This model is significant at an alpha level of .10 (F (3, $110)=2.504, \mathrm{p}=.063$, See Table 2-2). This model produced a low adjusted $\mathrm{R}^{2}$, indicating that it predicted approximately 3.80 percent of the variability in the dependent variable, the percent of immaterial compliance audit findings (Table 2-1). The variables of interest in this regression were experience and prior year experience. The independent variable for experience was significant at the .10 level (Experience, $\beta=.016, \mathrm{t}(1.807), \mathrm{p}=.073$ ) while prior year experience was not significant (Prior Year Experience, $(\beta=-.087, \mathrm{t}(-1.309), \mathrm{p}<.193)$. These results indicate limited support of $\mathrm{H} 2$. The data exhibit a positive relationship with experience as predicted, with a moderate level of significance. Alternatively, these data do not support H4. The sign of the coefficient is opposite that which was expected, nor does it achieve a sufficient level of significance.

TABLE 2-1

MODEL SUMMARY

\begin{tabular}{|l|c|c|c|}
\hline Model & R & R Squared & Adjusted R Squared \\
\hline 2 & $.253^{\mathrm{a}}$ & .064 & .038 \\
\hline
\end{tabular}

TABLE 2-2

ANOVA

\begin{tabular}{|l|c|c|c|c|c|}
\hline Model 2 & $\begin{array}{c}\text { Sum of } \\
\text { Squares }\end{array}$ & Df & Mean Square & F & Sig. \\
\hline Regression & .839 & 3 & .280 & 2.504 & $.063^{\mathrm{b}}$ \\
\hline Residual & 12.287 & 110 & .112 & & \\
\hline Total & 13.126 & 113 & & & \\
\hline
\end{tabular}

a. Dependent Variable: PerImmaterial

b. Predictors: (Constant), AuditHours, Same, Experience 


\section{TABLE 2-3 \\ COEFFICIENTS}

\begin{tabular}{|c|c|c|c|c|c|c|}
\hline Model 2 & B & Std. Error & Beta & $\mathbf{t}$ & Sig. & VIF \\
\hline (Constant) & .557 & .063 & & 8.818 & .000 & \\
\hline Experience & .016 & .009 & .179 & 1.807 & .073 & 1.158 \\
\hline PY Ex. & -.087 & .067 & -.128 & -1.309 & .193 & 1.131 \\
\hline Audit Hours & $-6.526 \mathrm{E}-5$ & .000 & -.202 & -2.162 & .033 & 1.025 \\
\hline
\end{tabular}

\section{DISCUSSION AND CONCLUSIONS}

This study examined the relationship of audit manager experience and the number of compliance audit findings reported. Additionally, this study considered the relationship of the audit managers' tenure with the agency, as predictors of the number of audit findings. The study conducted two separate regression studies with different dependent variables to examine the effect of the same independent variables on different aspects of the question of what effect does audit manager experience have on the number of compliance audit findings.

Complexity has been a significant factor to the number of compliance audit findings in previous studies. Branson, Nation, and Clark (2016) investigated, among other things, whether the complexity of a state agency affected the number of compliance audit findings and found it to be a factor. The current study included a variable related to complexity, the number of audit hours required to complete the audit and again found it to be significant. This enhances the validity of the remainder of the results derived from this data. Another incidental goal of this study was a replication of previous research done by Branson, Nation, and Stephens (2016). This study re-examines the question of whether the time required to complete a compliance audit was significant to the number of compliance audit findings. Replication enhances the validity of this study by relating the results of this study to previous literature. Branson, Nation, and Stephens (2016) examined the number of audit hours and what relationship it has with the number of audit findings in Illinois Auditor General Compliance examinations. Once again, this study finds that audit hours have a significant positive relationship with the number of audit findings (Table 13). This study found, as did Branson, Nation, and Stephens (2016) that audit time requirements influenced the number of findings

The first stated objective of this study is to examine the effect of audit manager experience, in the state government setting, on the findings presented in compliance audits of state governmental units. This hypothesis originated with Libby, and Frederick (1990). The literature examining auditor experience indicates that there are differing outcomes based on that auditor's experience level. The length of an audit manager's experience, according to previous research, affects judgement and decision-making performance. The results of the analysis indicated that the variable of interest proposed in H1, audit manager overall experience, had a significant influence on the number of audit findings, at the .10 significance level, in the expected direction. When total findings were regressed against the independent variable of interest, audit manager experience level, the results indicated that as governmental audit managers gain experience in that position they are more likely to produce increasing numbers of compliance audit findings. The results of this study support the proposed hypotheses (H1) that manager experience has an effect on the outcome of an audit. The authors hypothesized that the more experience an audit manager has, the more total findings that audit would yield (H1). The results presented in Table 1-3 support this hypothesis.

Second, the research predicted a relationship between the audit manager's overall experience level and the percentage of immaterial findings in the report. The historical literature suggests that auditor experience levels affect auditor judgements regarding materiality (Libby, and Frederick, 1990) and taskcomplexity (Abdolmohammadi and Wright, 1987). H2 proposes a positive relationship between the audit 
manager's experience level and the percentage of immaterial findings. In other words, auditors' decisions about what constitutes a material compliance audit finding is, according to Abdolmohammadi and Wright (1987), a less-structured task and thus more likely to be affected by experience level. The results of the test described in the second regression study indicated significant support for $\mathrm{H} 2$ at the .10 significance level.

Additionally, the study produced evidence about another variable of interest, prior year experience with the same agency audit client. This study provided some evidence that managers performing the same audit in consecutive engagement cycles will find fewer total findings versus managers performing the audit for the first time. Mautz and Sharaf (1961) explain this effect via complacency theory. The researchers examine these proposals in $\mathrm{H} 3$ and $\mathrm{H} 4$. $\mathrm{H} 3$ proposes that there will be an inverse relationship between prior-year experience with a client and the total number of findings. Prior literature in the public audit domain has indicated that audit failures are more likely early in tenure with a client, in congruence with the results of a study by Geiger and Raghunandan (2002). Based on the results of the previous work cited above, as auditors enter their second sequential engagement with a client they are more likely to experience an audit failure. Auditors auditing a client sequentially may become more confident or even overconfident in their audit work relating to that client or agency. This study found significant evidence of the same pattern in state agency audits at a significance level of .10. The results of this study indicate that audit managers who audit the same governmental agency sequentially, will produce fewer total compliance audit findings in the second year. This evidence provides support for H3.

Finally, the research examined H4, whether audit manager prior-year experience influences the percentage of immaterial findings. H4 proposes that there is a positive relationship between audit managers with prior-year client-agency experience and the percentage of immaterial findings in the compliance audit report. Unfortunately, the results of the test of this hypothesis do not indicate significant support for $\mathrm{H} 4$.

All empirical studies are subject to limitations, and this is no exception. First, this study is limited in scope. The researchers limited their examination to the compliance audit functions of the State of Illinois. Future researchers should be very circumspect about generalizing this study outside of the State of Illinois. Other states are not required to perform their administrative functions in the same manner as Illinois so there is almost certainly substantial variability regarding internal audit requirements amongst the several states. Additionally, this study used information collected from the proprietary data of the State of Illinois with the permission of the Director of Financial and Compliance Audits for the State of Illinois. Hence, this study assumes the veracity and accuracy of the information provided. Additionally, this study assumes that communication between the researchers and the Director resulted in adequate understanding of the nature of the requested information. Finally, the information requested from the Director is not necessarily confidential; however, it would have been very difficult to collect without the cooperation of the Director.

The purpose of this study was to examine and draw inferences about the effect of the level of the audit managers' experience on the number of total audit findings and the percentage of immaterial findings in the compliance audit report. The study examined independent variables of experience, previous-year experience, and the control variable required audit hours on the number of reported compliance audit findings. Tests of the primary independent variable of interest, total compliance audit findings produced support for $\mathrm{H} 1$ as well as the secondary hypotheses $\mathrm{H} 2$ and $\mathrm{H} 3$. These tests provide support for the proposal that experience has an effect on governmental compliance audits in much the same way as has been found in audits of public companies.

\section{ENDNOTE}

1. The authors would like to acknowledge the generous assistance of Ms. Jane Clark, the Director of Financial and Compliance Audits for the State of Illinois, without whom this study would have been impossible. 


\section{REFERENCES}

Abdolmohammadi, M., \& Wright, A. (1987). An Examination of the Effects of Experrience and Task Complexity on Audit Judgment. The Accounting Review, 62(1), 1-13.

Aikins, S. K. (2017). An Investigation of the Relationships Between Time Invested in Government Internal Audit Projects and Audit Outcomes. Journal of Accounting and Finance, 17(7), 159-173.

Branson, L., Decker, J. L., \& Green, M. (2011). To Find or Not to Find: Public Accounting Auditors versus Governmental Auditors. Review of Business Information Systems, 15(4), 5-10.

Branson, L., Nation, F., \& Clark, D. (2016). An Analysis of Compliance Audits in State Government. International Journal of Business, Accounting, \& Finance, 10(1), 1-11.

Branson, L., Nation, F., \& Rothe, M. (2018). An Empirical Study of Factors Effecting Governmental Compliance Audit Findings. The International Journal of Business, Accounting, and Finance, 12(1), 17-28.

Branson, L., Nation, F., \& Stephens, J. (2016). Compliance Audits: A Study of the Relation Between Audit Findings and Audit Hours. International Journal of Business, Accounting and Finance, $10(2)$.

Carcello, J. V., \& Nagy, A. L. (2004). Audit Firm Tenure and Fraudulent Financial Reporting. Auditing: A Journal of Practice and Theory, 23(2), 55-69.

Deis, Jr., D. R., \& Giroux, G. (1996). The Effect of Auditor Changes on Audit Fees, Audit Hours, and Audit Quality. Journal of Accounting and Public Policy, 15, 55-76.

Geiger, M. A., \& Raghunandan, K. (2002). Audit Tenure and Audit Reporting Failures. Auditing: A Journal of Practice and Theory, 21(1), 67-78.

Ho, J. L. (1994). The Effect of Experience on Concensus of Going-Concern Judgments. Behavioral Research In Accounting, 6, 160-171.

Kwon, S. Y., Lim, Y., \& Simnett, R. (2014). The Effect of Mandatory Audit Firm Rotation: Empirical Evidence From the Korean Audit Market. Auditing: A Journal of Practice and Theory, 33(4), 167-195.

Libby, R., \& Frederick, D. M. (1990). Experience and the Ability to Explain Audit Findings. Journal of Accounting Research, 28(2), 348-367.

Mautz, R. K., \& Sharaf, H. A. (1961). The Philosophy of Auditing. Sarasota: American Accounting Association.

Nau, R. (2018). Linear Regression Models. Retrieved from Statistical Forecasting: Notes on Regression and Time Series Analysis: http://people.duke.edu/ rnau/testing.htm

Palmrose, Z.-V. (1986). Audit Fees and Auditor Size: Further Evidence. Journal of Accounting Research, 24(1), 97-110.

Shelton, S. W. (1999). The Effect of Experience on the Use of Irrelevant Evidence in Auditor Judgment. The Accounting Review, 74(2), 217-224.

Suhayati, E. (2012). The Influence of Audit Fee, Audit Time Budget Pressure and Public Accountant Attitude on the Public Accountant Dysfunctional Behavior and its Implications on Audit Quality Survey on "Small" Scale Public Accounting Firms in Java. Journal of Global Management, 4(1), $1-24$.

The Pennsylvania State University. (2017). Stat 501 Regression Methods. Retrieved from Penn State Eberly College of Science: https://onlinecourses.science.psu.edu/stat501/node/347

Weber, R. (1980). Some Characteristics of the Free Recall of Computer Controls by EDP Auditors. Journal of Accounting Research, 18(1), 214-241. 